\title{
Failure of expansion of covered self-expanding metal stent during tracheal stenting: Case report
}

\author{
Chee Kiang Phua, Elmer Algoso Reyes, John Abisheganaden, Albert YH Lim, Akash Verma* \\ Department of Respiratory and Critical Care Medicine, Tan Tock Seng Hospital, Singapore
}

Received: September 28, 2015

Accepted: November 5, $2015 \quad$ Online Published: November 11, 2015

DOI: $10.5430 /$ crim.v3n1p1

URL: http://dx.doi.org/10.5430/crim.v3n1p1

\begin{abstract}
Twenty to thirty percent of patients with lung cancer present with central airway obstruction. Self-expanding metal stent (SEMS) is effective for recanalization of such lesions when caused by extrinsic compression, with the advantage of ease of deployment with a flexible bronchoscope. We report a case of failure of expansion of a SEMS during tracheal stenting. To our knowledge this is a first report documenting this rare complication.
\end{abstract}

Key Words: Self-expanding metal stent, Flexible bronchoscope, Central airway obstruction, Tracheal stenting, Failure of expansion

\section{INTRODUCTION}

Metallic stents is an effective strategy for recanalization of the malignant airway obstruction which occurs in $20 \%$ to $30 \%$ of patients with lung cancer, contributing to dyspnoea, collapsed lung, and post obstructive pneumonia. ${ }^{[1-3]}$ Recanalization of the obstructed airway by a stent has been proven to relieve dyspnoea and delay respiratory failure, allowing definitive therapy for cancer such as chemotherapy or radiotherapy to be carried out. ${ }^{[3-5]}$

Where silicone stents are preferred in benign diseases but require rigid bronchoscopy, metal stents inserted via flexible bronchoscopy are a feasible alternative for the recanalization of malignant central airway obstruction with palliative intent. They are deployed either via a balloon-expandable or self-expanding metal stent (SEMS) system, and are available in either uncovered or covered forms. The attractiveness of SEMS lies in their feasibility of deployment via a flexible bronchoscopy which can be performed by most pulmonolo- gists, in comparison to rigid bronchoscopy, which is performed by fewer pulmonologists. They are also known for reduced risk of mucus plugging, migration and favourable internal/external diameter ratio. SEMS include Walls tent, Gianturco, Ultraflex and Aero. ${ }^{[3]}$

However, complications associated with SEMS are not uncommon and include occlusion by granulation tissue formation, tumour ingrowth, difficult retrieval, stent fracture, migration, haemoptysis and infectious tracheobronchitis. ${ }^{[4,6,7]}$ We report a rare case of failure of expansion of a covered SEMS during tracheal stenting.

\section{Case history}

A 69-year-old male with a background of diabetes mellitus, hypertension, dyslipidaemia and diverticulosis presented in April 2014 for chronic cough and weight loss. Chest radiography was largely unremarkable except right hilar prominence. However, in view of weight loss, a computed tomography

\footnotetext{
*Correspondence: Akash Verma, MRCP; Email: Akash_Verma@ttsh.com.sg; Address: Department of Respiratory and Critical Care Medicine, Tan Tock Seng Hospital, 11 Jalan Tan Tock Seng, Singapore 308433, Singapore. 
(CT) thorax, abdomen and pelvis was performed and showed a large heterogeneous mass lesion in the right lower paratracheal region, superior to the right upper lobe bronchus. It measured $4.9 \mathrm{~cm} \times 6.4 \mathrm{~cm} \times 6.0 \mathrm{~cm}$ with tracheal displacement to the left and narrowing of the lumen of the lower trachea measuring $1.5 \mathrm{~cm} \times 0.5 \mathrm{~cm}$ (see Figure 1). There were no malignant cells seen on his sputum cytology and work up for tuberculosis was unremarkable on his sputum acid fast bacilli smears/cultures and tuberculosis polymerase chain reaction $(\mathrm{PCR})$.

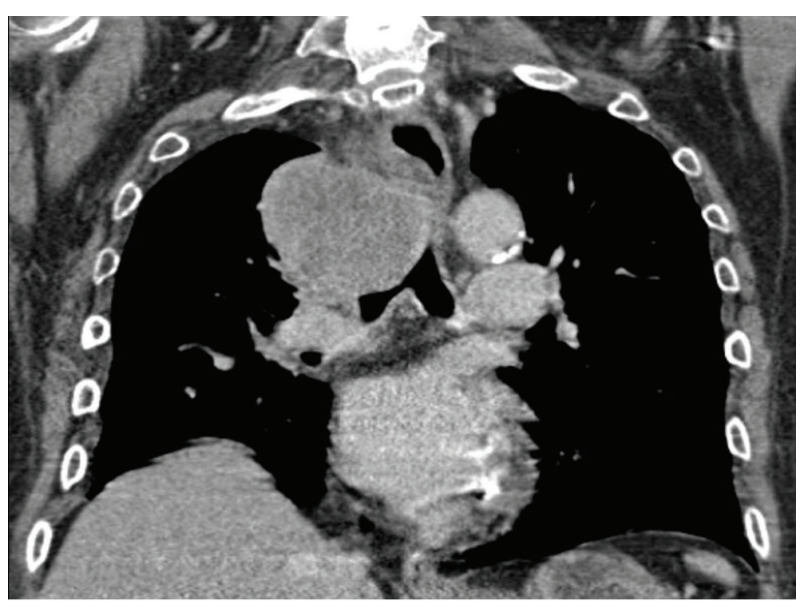

Figure 1. Computed tomography thorax showing a large a mass lesion in the right lower paratracheal region with left sided tracheal displacement and narrowing

Bronchoscopic assessment confirmed a narrowed distal trachea. Vertical length was about $15 \mathrm{~mm}$ and diameter was about $8 \mathrm{~mm}$. There was partial occlusion of the right main bronchus along with a submucosal nodule. There were no endobronchial lesions seen in the remaining bronchial trees.

He underwent a video-assisted mediastinal lymph node and right paratracheal mass biopsy. Histology reported a poorly differentiated carcinoma with squamous features. Bone scan and brain magnetic resonance imaging did not reveal any evidence of metastasis. He was started on radiotherapy and chemotherapy (gemcitabine and carboplatin). Following this, a CT thorax showed reduction in the size of right paratracheal mass, and there was improvement in his functional status. A right thoracotomy with right upper lobe mass resection was attempted but abandoned due to the intraoperative findings of the mass invading into the superior vena cava. Decision was made to continue with palliative chemotherapy and radiotherapy for his superior vena cava obstruction.

Four months later he presented with worsening cough and dyspnoea. Repeat CT thorax showed interval increase in size of the right para-tracheal mass with associated mass effect and trachea narrowing, narrowest dimension measuring $1 \mathrm{~cm}$ (see Figure 2).

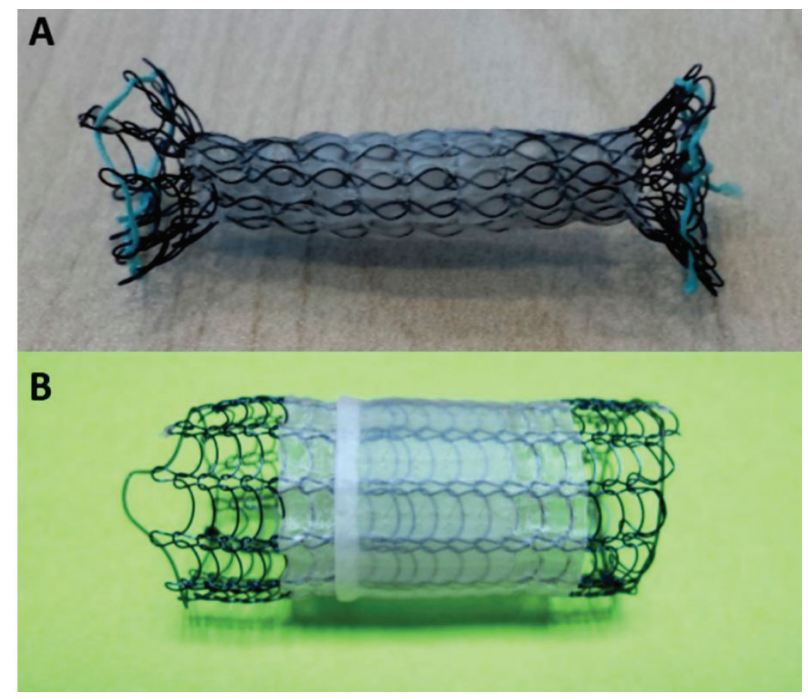

Figure 2. A) Failed expansion of the covered Ultraflex metal stent; B) Sample of normally expanded covered Ultraflex metal stent for comparison

Radiotherapy was started. In view of worsening symptoms and findings of tracheal narrowing from extrinsic compression, tracheal stenting was planned in conjunction. Based on CT findings, an Ultraflex covered self-expandable metal stent of $16 \mathrm{~mm}$ diameter and $40 \mathrm{~mm}$ length was chosen to be placed in distal trachea. Upon bronchoscopic confirmation of the dimensions of the stenosed segment of the trachea, Ultraflex covered self-expandable metal stent $(16 \mathrm{~mm} \times 40$ $\mathrm{mm}$ ) was deployed in the distal trachea under fluoroscopy guidance by standard technique. ${ }^{[4,8]}$ However, upon removal of the stent delivery catheter and inspection of the trachea to confirm placement, stent was found to be loose and mobile in the trachea. It was promptly removed from the trachea. Examination of the removed stent revealed that it had not expanded despite traction of the nylon thread. Decision was made not to re-insert a new stent but continue ongoing radiotherapy, and re-consider stenting in another sitting.

\section{Discussion}

Complications associated with self-expanding metal stents are well documented. In a retrospective analysis of 68 patients undergoing Ultraflex self-expanding metal stents insertion for malignant tracheobronchial stenosis, complications included haemorrhage originating in the area of the stent placement during the insertion itself (1 patient), mild haemoptysis (5 patients), stent migration (4 patients), severe granulation tissue ( 3 patients), pneumonia ( 2 patients), odynophagia, respiratory failure, stent occlusion, and deploy- 
ment failure (1 patient in each case). There were no episodes of fistula formation, lobe collapse, pneumothorax or sudden death. $^{[4]}$

In another study of 82 patients, Saad et al., reported the occurrence of infection in $15.9 \%$, obstructive granulomas (14.6\%), and migration in 4.7\%. ${ }^{[6]}$ Infectious tracheobronchitis is another commonly reported complication, which can be effectively treated with antibiotics. ${ }^{[7]}$ However, others have also reported significant morbidity and mortality resulting from lower respiratory tract infections post stenting. ${ }^{[9]}$

Failure of expansion of a SEMS in tracheobronchial stenting is rare and published literature on this complication is sparse. McGrath et al. have reported deployment failure in one case but did not describe the details. ${ }^{[4]}$ Dimofte et al., have reported incomplete deployment of an oesophageal expandable metallic stent in a patient with oesophageal malignant stenosis, which was attributed to malfunction of the stent deployment system. ${ }^{[10]}$ In our case, the reason for the expansion failure of the stent could not be identified. The stent was within the expiry date, and it was stored in the cli- mate controlled environment at the temperature of 23 degree centigrade in the operation theatre. Two likely explanations can be put forth for the failure of stent expansion. One, the tight stenosis of the trachea itself may not have allowed the stent to open due to its compressive effect on the stent. Second, stent may have failed to expand due to its own technical defect. We report a rare and unexpected failure of SEMS which could result in significant morbidity and cost to the patient. Fortunately our patient did not suffer any significant complication and the un-expanded stent could be easily retrieved.

\section{Conclusion}

SEMS is an effective strategy for palliation of malignant central airway obstruction, due to ease of deployment. However, failure of expansion in the airway after deployment can be a potentially hazardous complication. Although rare, physicians need to be aware of this unusual complication and ensure availability of the service of rigid bronchoscopy to retrieve and reinsert the stent safely, should the need arise.

\section{REFERENCES}

[1] Ernst A, Feller-Kopman D, Becker HD, et al. Central Airway Obstruction. Am J Respir Crit Care Med. 2004; (169): 12781297. PMid:15187010 http://dx.doi.org/10.1164/rccm. 20 0210-1181S0

[2] Marchese R, Poidomani G, Paglino G, et al. Fully covered selfexpandable metal stent in tracheobronchial disorders: clinical experience. Respiration. 2015; 89(1): 49-56. PMid:25592654 http: //dx.doi.org/10.1159/000368614

[3] Sosa AF, Michaud GC. Metallic stents in the airway: should we continue to use them and can we remove them? Curr Respir Care Rep. 2013; 2: 54-60. http://dx.doi.org/10.1007/s13665-0 12-0036-7

[4] McGrath EE, Warriner D, Anderson P. The insertion of self expanding metal stents with flexible bronchoscopy under sedation for malignant tracheobronchial stenosis: a single-center retrospective analysis. Arch Bronconeumol. 2012; 48(2): 43-8. PMid:22137422 http://dx.doi.org/10.1016/j.arbres. 2011.09.008

[5] Al-Ayoubi AM, Bhora FY. Current readings: the role of stenting in tracheobronchial disease. Semin Thorac Cardiovasc Surg. 2014; 26(1): 71-5. PMid:24952760 http://dx.doi.org/10.1053/j.s emtcvs. 2014.02 .004
[6] Saad CP, Murthy S, Krizmanich G, et al. Self-expandable metallic airway stents and flexible bronchoscopy: long-term outcomes analysis. Chest. 2003; 124(5): 1993-9. PMid:14605078 http://dx.doi .org/10.1378/chest.124.5.1993

[7] Dasgupta A, Dolmatch BL, Abi-Saleh WJ, et al. Self-expandable metallic airway stent insertion employing flexible bronchoscopy: preliminary results. Chest. 1998; 114(1): 106-9. PMid:9674455 http://dx.doi.org/10.1378/chest.114.1.106

[8] Madden BP, Datta S, Charokopos N. Experience with Ultraflex expandable metallic stents in the management of endobronchial pathology. Ann Thorac Surg. 2002; 73: 938-44. http://dx.doi.org/1 $0.1016 / \mathrm{S} 0003-4975(01) 03460-9$

[9] Ost DE, Shah AM, Lei X, et al. Respiratory infections increase the risk of granulation tissue formation following airway stenting in patients with malignant airway obstruction. Chest. 2012; 141(6): 1473-81. PMid:22194585 http://dx.doi.org/10.1378/chest .11-2005

[10] Dimofte G, Moldovanu R, Crumpei F, et al. Incomplete deployment of an expandable metallic stent in a patient with esophageal malignant stenosis. J Gastrointestinal Liver Dis. 2010; 19(3): 325-8. PMid:20922200 